UNITED STATES

DEPARTMENT OF THE INTERIOR

GEOLOGICAL SURVEY

\title{
A RECONNAISSANCE ASSESSMENT OF PROBABILISTIC EARTHQUAKE ACCELERATIONS AT THE NEVADA TEST SITE
}

\section{$\mathrm{By}$}

\begin{abstract}
David M. Perkins, ${ }^{1}$ Paul C. Thenhaus, ${ }^{1}$ Stanley L. Hanson, ${ }^{1}$ and
\end{abstract} S. T. Algermissen ${ }^{1}$

\section{DISCLAIMER}

This report was prepared as an account of work sponsored by an agency of the Unted States Government. Neither the United States Government nor any agency thereof, nor any of their employees, makes any warranty, express or implied, or assumes any legal liability or responsibility for the accuracy, completeness, or usefulness of any information, apparatus, product, or process disclosed, or represents that its use would not infringe privately owned rights. Reference herein to any specific commercial product, process, or service by trade name, trademark, manufacturer, or otherwise does not necessarily constitute or imply its endorsement, recommendation, or favoring by the United States Government or any agency thereof. The views and opinions of authors expressed herein do not necessarily state or reflect those of the United States Government or any agency thereof.

1 Branch of Geologic Risk Assessment, Denver, CO 


\section{DISCLAIMER}

This report was prepared as an account of work sponsored by an agency of the United States Government. Neither the United States Government nor any agency Thereof, nor any of their employees, makes any warranty, express or implied, or assumes any legal liability or responsibility for the accuracy, completeness, or usefulness of any information, apparatus, product, or process disclosed, or represents that its use would not infringe privately owned rights. Reference herein to any specific commercial product, process, or service by trade name, trademark, manufacturer, or otherwise does not necessarily constitute or imply its endorsement, recommendation, or favoring by the United States Government or any agency thereof. The views and opinions of authors expressed herein do not necessarily state or reflect those of the United States Government or any agency thereof. 


\section{DISCLAIMER}

Portions of this document may be illegible in electronic image products. Images are produced from the best available original document. 


\author{
A Reconaaissance Assessment \\ of Probabilistic Earthquale Accelerations \\ at the Nevada Test Site
}

by

\begin{abstract}
We have made two interim assessments of the probabilistic ground-motion hazard for the potential nuclear-waste disposal facility at the Nevada Test site (NTS). The first assessment used historical seismicity and generalized source zones and source faults in the immediate vicinity of the facility. This model produced relatively high probabilistic ground motions, comparable to the higher of two earlier estimates by Rogers and others (1977), which was obtained by averaging seismicity in a 400-km-radius circle around the site. The high ground-motion values appear to be caused in part by nuclear-explosion aftershocks remaining in the catalog even after the explosions themselves have been removed.
\end{abstract}

The second assessment used particularized source zones and source faults in a region substantially larger than NTS in order to provide a broad context of probabilistic ground motion estimates at other locations of the study region. Source faults are mapped or inferred faults having lengths of 5 zm or more. Source zones are defined by boundaries separating fault groups on the basis of direction and density. For this assessment, earthquale recurrence has been estimated primarily from historic seismicity prior to nuclear testing. Long-term recurrence for large-magnitude events is constrained by geological estimates of recurrence in a regime in which the large-magnitude earthquakes would occur with predoninately normal mechanisms. The probabilistic ground motions from this model are much smaller, comparable to the lower of the two 1977 estimates, which was obtained by assigning to the test-site region an average seismic rate equivalent to that of Nevada-Basin-and-Range seismicity occurring outside of the "Nevada Seismic Zone."

The two assessments yield significantly different estimates of probabilistic ground motions-exceedances of given levels of ground motion differ by as much as a factor of ten. Some of the difference could be eliminated by removing from the 
catalog aftershochs initiated by nuclear tests, thus somewhat reducing the earthquake recurrence rate in the first model. A further reduction in the difference would result if one accepted an interpretation of the tectoric regime permitting large strire-slip earthquakes, thus allowing an increase in the recurrence rate of large magnitude earthquakes in the second model.

\section{Introduction}

The benefit of probabilistic ground-motion studies in site-hazard assessment is best seen by contrasting probabilistic assessment with deterministic assessment. In deterministic assessment, geological and geophysical studies are used to identify the known faules and to estimate the maximum credible magnitude on them. Then, using a suitable attenuation function to estimate the ground motion at a given distance from a given magnitude earthquak, one obtains the roximum ground motion to be expected at the site owing to the maximum magnitude event on each of the various geologic structures identified Several objections might be of fered to the use of the results of a deterministic study. For one, we do not know enough about the state of stress, or about the capacity for the materials to resist the seismic stress, to be able to assess a true maximum magnitude for each of the known geologic structures. Furthermore, we cannot Jet be assured of finding all the relevant geologic structures.

In contrast, in a probabilistic assessment, the technique takes into account not only the maximum earthquares on known geologic structures but also all the other magnitudes possible on these structures. In addition, the probabilistic technique permits modelling random earthquakes to represent unknown geologic structures. (Known geologic structures are usually modalled by "\$ource faults:" randomly located earthquakes are usually modelled by "source zones", although random fauls can also be modelled by source (aults.) All earthquakes modelled are associated with an appropriate annul recurrence rate for each possible magnitude level. In this manner, the probabilistic ground-motion technique provides a contezt in which it is possible to assess the exceedance probability of the raximum deterministic ground motion at the site. The probabilistic ground-motion assessment also provides the exceedance probabilities for any other level of ground motion. This permits the selection of design ground motions lower than the maximum deterministic ground motions, given a specific acceptable exceedance probability during a specific period of time. 
The heart of a probabilistic ground-motion-hazard assessment is the model of sources and rates for future earthquake occurrences. Just as deterministic assessments can be criticized for being subject to different interpretations on what structures are capable and what maximum magnitudes are credible, analogous objections can be made to probabilistic assessments. More than one model can be used for sources and rates. The value of any particular model is not only what probabilistic ground-motion estimates it gives us, but also what it can tell us about the elements which most affect the probabilistic ground-motion results. We call the estimates of this present report "xeconnaissance" assessments because we are not only interested in new estimates of the level of ground-motion hazard, but also in determining the relative importance of various aspects of the new models-the details of the local seismicity estimates and the configuration and specificity of the local seismic sources. This information will guide us making more accurate models in the future.

This present work is an extension of earlier probabilistic ground-motion estimates (Rogers and others, 1977), which were intended to provide perspective for a deterministic maximum acceleration value at a potential nuclear-waste repository at the Nevada Test Site (NTS). In the previous work, two estimates were provided, both based on very simple models of regional seismicity. The first of the two earlier estimates presented the probabilistic consequences of a hypothesis that any earthquake that had occurred within a $400-\mathrm{km}$ radius of the test site could occur with equal likelihood anywhere within this $400-\mathrm{km}$ radius. This model allows the more active areas within the $400-\mathrm{km}$ radius to migrate from their present positions, but makes their possible emplacenent near the site no more or less likely than anywhere else. The $400-\mathrm{km}$ radius includes earthquakes in portions of southern California and Nevada where large, throughgoing faults are known to produce recurrent large earthquakes. Because comparable features are not known to exist in the vicinity of NTS, this model is not tenable as a description of the seismicity in this area, but might be presumed to produce a reasonable upper-bound estimate for probabilistic ground-motion hazard at NTS.

The second of the estimates of Rogers and others (1977) resulted from the hypothesis that the seismicity in the NTS vicinity is equal to the relatively low, average-level seismicity found outside of the active Nevada Seismic Zone in the Basin-and-Range province of Nevada. Without a detailed model of seismic sources in the NTS vicinity, this hypothesis might reasonably be considered to give a prudent lower-bound estimate of seismic rate. 


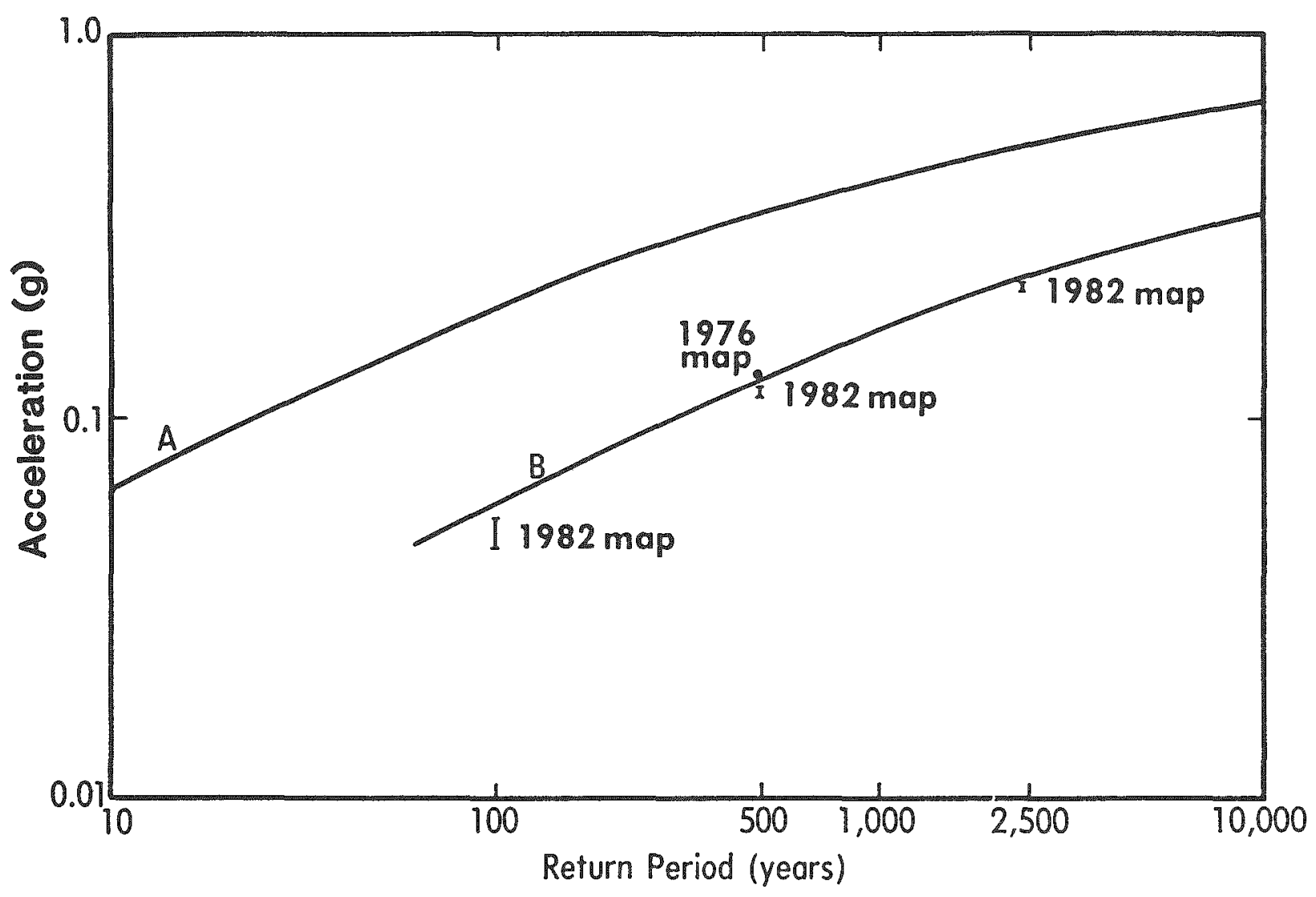

Figure 1. Probabilistic ground-motion estimates from prior studies.

Curves: Results assuming uniform seismicity for historical seismicity found within (A) 400-km radius and (B) Basin-and-Range seismicity, exclusive of Nevada Seismic Zone (Rogers and others, 1977). Dot and bar estimates are derived from national seismic-hazard maps (Algermissen and Perkins, 1976 and Algermissen and others, 1982). Succeding figures showing results from the present study will also show curves $\mathbb{A}$ and $B$ for reference. 
The probabilistic ground-motion results of the two 1977 models are shown by the two curves in figure 1. In addition, point values from the national probabilistic ground-motion maps of Algermissen and Perkins (1976) and Algermissen and others (1982) are plotted on the same figure. Because the estimates in figure 1 were produced by the same techniques, using the same attenuation function, they are directly comparable with one another. The 1977 estimates result from generalized regional models. In contrast, the present study uses local models. In order to emphasize the effect of the new models in our present study, the probabilistic ground motions will again be calculated using the same techniques as before.

\section{New Local Models}

Model 1: A generalized site-vicinity model.

The purpose of this model is to provide a preliminary assessment of the relative importance of the various sources which could be modelled in the vicinity of the potential waste site. For this purpose, the model can be general rather than specific as to the location and configuration of the various sources. The following sequence of considerations justifies the generality of the model:

1. If the seismicity near an arbitrary site is sufficiently high, the probability density function of ground motions at the site will be dominated by the contribution from the nearest sources. Thus, we can ignore detailed modelling of distant sources.

2. In particular, to the east and southeast of the potential waste site, the monitored seismicity is high and, as a conservative estimate, can be assumed to be attributable to hypothetical systems of faults trending north and northeast, parallel to mapped faults in the same area. If modelled as long, throughgoing faults that can sustain ruptures long enough to generate earthquakes of magnitude Ms $=7$ or greater, these faults will be the predominant sources for ground motions up to the size given by the maximum magnitude earthquake on the nearest modelled fault.

3. Larger ground motions than those produced by the faults modelled in 2 can be generated from two kinds of earthquakes: (a) earthquakes on unknown structures closer to the site, and (b) larger-magnitude earthquakes further from the site. The model needs to provide for these kinds of earthquakes. 
4. The results from these general sources can be used as a guide for a more detailed and accurate model.

Guided by the considerations listed above, four types of generalized sources were chosen for the initial model (fig. 2):

1. Hypothetical subparallel source faults, roughly $5 \mathrm{~km}$ apart, were drawn in the areas to the southeast and east of the site, with striles parallel to mapped faults in these areas, and having strike lengths about as long as the dimensions of the NTS reservation. On these faults, earthquakes larger than magnitude 5.8 are assumed to produce finite-length ruptures, with rupture lengths a function of magnitude.

2. Source zones were drawn to represent the possible locations of short-rupture earthquakes in the three calderas at the west side of the NTS.

3. A large east-west-trending seismic source zone was drawn to provide a uniform-seismicity source for background earthquakes occurring outside of the calderas. The site of the potential waste facility lies near the boundary between. this zone and one of the calderas in 2. Hence, zero-distance earthquakes are possible in this model from random earthquakes in one of these zones.

4. Finally, a source zone and source fault were drawn in order to provide seismicity attributable to the Death Valley-Furnace Creek fault zone.

The seismicity observed in the area covered by the model was fitted to the Gutenberg-Richter relationship,

$$
\log \mathbf{N}=\mathrm{a}+\mathrm{bM}
$$

Where $\mathrm{N}$ is the amnual rate of earthquakes occurring in the magnitude interval $M-0.3-M+0.3$, and $M$ is the surface wave magnitude. The fit seismicity was allocated among the various source zones according to the observed number of earthquakes above magnitude 4.0. (In the decades after 1960, there seems to be contamination from nuclear-explosion aftershocks in some magnitude ranges above magnitude 4.0. Where this seexaed obvious, all the earthquakes in these magnitude ranges for these decades were removed from the analysis and allocation.) In source zones containing faults, that part of the allocated seismicity having magnitudes larger than 5.8 was assigned to the faults and modelled as ruptures: allocated seismicity having magnitudes lower than 5.8 was assigned to the source zones and modelled as point sources. For source zones having no modelled faults, seismicity 


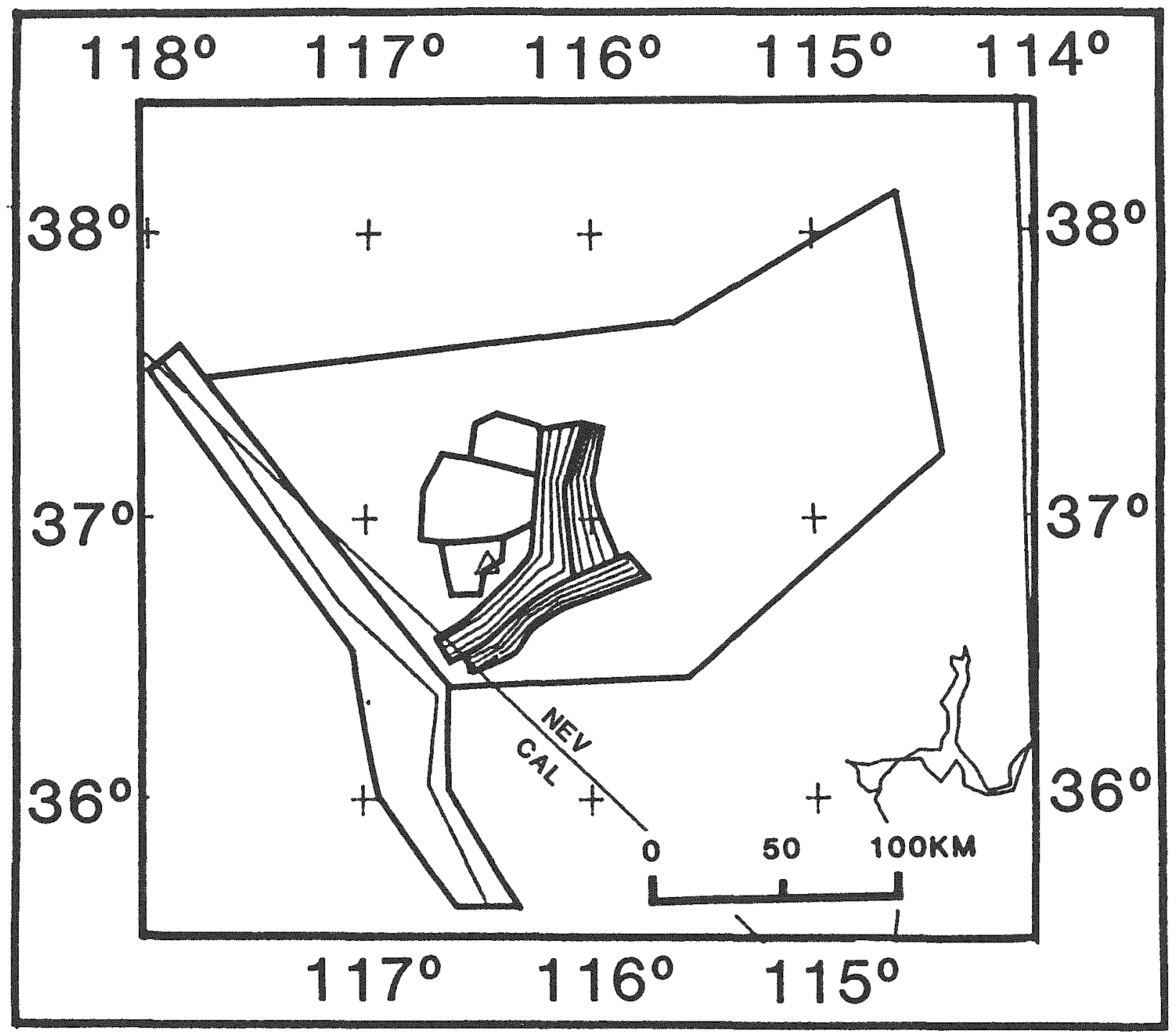

Figure 2. Source zones (bounded by heavy lines) and source faults (light lines within source zones) assumed for Model 1: a generalized site-vicinity model. The model is intended to represent only seismicity likely to dominate site ground motions. Major local seismicity is placed on three subparallel source-fault systems representing trends in surface faults found east and southeast of the potential waste site (small triangle). Earthquakes are modelled as finite ruptures on these source faults. Seismicity in three nearby calderas is represented by source zones for point ruptures. In addition there is a large background zone. Finally, across the Nevada-California border, there is a source zone and a source fault for seismicity on the Death Valley-Furnace Creek fault system. 


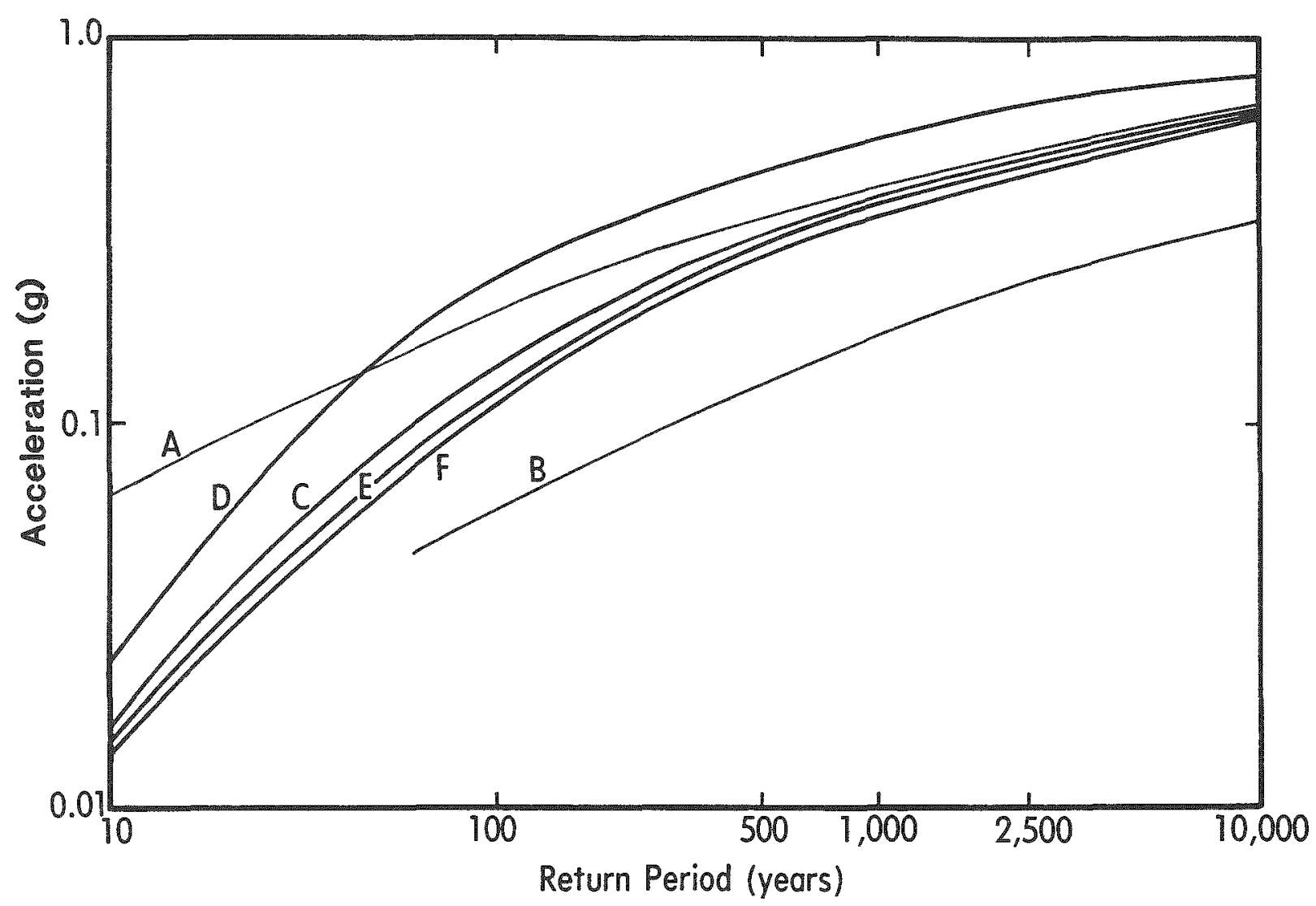

Figure 3. Probabilistic ground-motion curves for various assumptions on maximum magnitudes. Curves $A$ and $B$ are reference curves from figure 1. (C), Maximum magnitude on all source zones is 7.6 ; (D), Maximum magnitude is 7.6 , but rate above magnitude 7.0 is ten times that used in (C). (The purpose is to simulate effect of "characteristic earthquakes" with rates larger than those that can be extrapolated from Richter-law fits to historical data. (E), Maximum magnitude on all sources is 7.0; (F), Maximum magnitude on source faults is 7.0; maximum magnitude on source zones is 6.4. Steep portion of curves is due to influence of faults. Behavior for higher ground motion has lower slope, a sign of influence of local point sources. 
for all magnitudes was modelled as point sources.

Probabilistic ground-motion calculations were made for various upper-bound magnitudes. Figure 3 shows probabilistic ground-motion curves, acceleration vs. return period for various assumed upper-bound magnitudes. Curves $\mathbf{A}$ and $\mathbf{B}$ are those curves from the 1977 models, retained as reference from figure 1. Curve $C$ shows the results for model 1 when the upper-bound magnitude is 7.6 on all sources. Curve D allows the same maximum magnitude, except that in the range 7.0-7.6 the rate is ten times the rate obtained from the Gutenberg-Richter fit. The purpose is to model the sensitivity of the results to the effect of "characteristic earthquakes," whose rates would be greater than that given by a Gutenberg-Richter fit to lower-magnitude data. Curve $\mathbf{E}$ shows the result when the maximum magnitude on all the sources is 7.0 ; Curve $F$ shows the result when the maximum magnitude allowed on modelled faults is 7.0 , and the maximum magnitude allowed in source zones is limited to 6.4. These different choices allow us to test the sensitivity of the results to changes in maximum magnitude.

In general, model 1 produces results that, at long return periods, are comparable to curve A from the 1977 models. Recall that the source model for curve A averages all the historical seismicity occurring in a $400-\mathrm{km}$ radius around. the site, including some California activity and some of the Nevada-Seismic-Zone activity, both areas characterized by high seismicity rate and large-magnitude, long-rupture events. It is therefore surprising that model 1 should produce results comparable to curve $\mathbf{A}$. The comparison of our curves with curve $\mathbb{A}$ is not much affected by the changes in maximum magnitude. This fact suggests that the comparability is not so much a function of upper-bound magnitude but of high seismicity rates used in model 1. These rates may be high for two reasons:

1. At the low magnitudes, the rates may be too high due to aftershocks from nuclear explosions. We have been shown data supporting the assertion that aftershocks having magnitudes as great as 5.0 are experienced at distances as far as 50 km from nuclear-test explosions, as long as 7 days after the explosions.

(A. M. Rogers and S. C. Harmsen, U.S. Geological Survey, oral communa, 1984). We concluded that seismicity from the entire period of testing is not suitable for hazard studies unless explosion aftershocks have been removed.

2. At the higher magnitudes, rates may be too high because they are unconstrained by data. The rates above magnitude 5.2 are set by extrapolation according to the Gutenberg-Richter fit (b-value -0.72). Consultations with geologists familiar with the test site have impressed upon us the fact that earthquales of magnitudes 
about 7 and greater should recur in the model area only a very few times in 10,000 years (W. J. Carr and E.H. Anderson, U.S. Geological Survey, oral commun., 1984). This rate is about ten times less than the rate extrapolated from the Gutenberg-Richter fit. A successor model should take this geological information into account.

Inspection of the curves of figure 3 shows that the faults are not contributing significantly to the highest ground motions: Curve $A$ is the result of a point-source model and has the general characteristics of such curves-a low slope at low ground-motion values and a gradual lessening in slope with increasing return period The model-1 curves all show steep initial slopes, characteristic of rupture-source models; however, at the higher ground-motion values (longer return periods), the curves roll over to slopes characteristic of point-source models. This behavior tells us that the parallel fault systems are contributing to the relatively high excedance probabilities for the lower ground-motion values, but that the probabilities for the higher ground motion are governed by the seismicity of the point sources assumed for the source zones surrounding the site.

Thus, the high ground-motion ezceedance rates produced by model 1 are governed by two types of sources. At the highest ground-motion levels, it is reasonable to assume that explosion aftershocks are causing rates of seismicity to be allocated to the source zones adjacent to the site. There is no reason to expect seismicity rates for these source zones to be significantly higher than an average Basin-and-Range rate, which would produce exceedance rates comparable with those given by curve $\mathbb{B}$.

At somewhat lower ground motions, it is reasonable to infer that there is excessive activity assigned to the parallel fault systems. This excessive activity probably has three causes. Explosion aftershocks will produce excessive seismic rates here as well as at locations nearer to the site. Furthermore, the excessive seismicity of the higher magnitudes will have greater effect on ground-motion excedances at the site from rupturing sources than from point sources. (Given that an earthquale occurs at some point, it can rupture closer to the site.) The generality of the faults also produces excessive seismicity. These closely spaced faults are probably producing more seismicity per unit area near the site than would the more sparsely spaced mapped faults in the same area. 
The generality of model 1 brings with it another disadvantage. It does not allow us to determine whether the probabilistic ground-motion estimate for the site is relatively high or low compared to estimates for other locations in the test site vicinity. The source faults and zones of a generalized model cannot do this: rather, we need a particular model, one that attempts to deal more realistically with real data in the test-site vicinity. Since 1978 , seismicity has been closely monitored in the NTS vicinity (Rogers and others, 1983). Can we use this seismicity to improve our view of the relative zonal seismicity rate? In testiag this idea, we compared the relative areal seismic rates used in model 1 with the relative rates of seismicity in the same zones for magnitudes 3.4 and above since 1978. Allocation of seismicity according to post-1978 rates would produce ground motions at the Silent-Canyon-Caldera source zone about twice what would have been calculated under model 1; the background zone ground motion would be about half that calculated under model 1. This suggests to us that the monitored seismicity has strongly swung the seismicity balance toward those regions in which the nuclear tests are being conducted. Therefore, we should not use the post-1978 seismicity data until explosion-induced seismicity has clearly been removed from that data.

In summary, model 1 produces probabilistic ground motions at the potential waste-disposal site comparable to curve $\mathbf{A}(f i g .2)$ from the 1977 study. This result appears to be due to the excessively high seismicity rate adopted for source zones in the vicinity of the site. This excessive seismicity is due in part to contamination from nuclear-explosion aftershocks and in part to excessive rates for larger-magnitude events because of lack of constraint from geologic estimates. The generalized model itself contributes to the excessive exceedance rate by placing too many long faults near the site. We will now use this critique of model 1 as a guide in specifying a successor model. 
Model 2: A particularized subregional seismic model for the NTS vicinity.

The shortcomings of model 1 led us to specify a second model based upon the following considerations:

1. In order to provide a context for probabilistic ground motions calculated for the potential waste-disposal site, probabilistic ground-motion-hazard estimates were to be made not only for the waste-storage site, but also for three other sites chosen to demonstrate other geometrical relationships with respect to less active and more active faults in the study region. Accordingly, an earthquake-occurrence model was needed for an area of sufficient size to contain all these sites and the earthquake sources having significant contributions to the ground motions expected. at those sites.

2. This model should use historical seismicity which is uncontaminated by nuclear-test aftershocks and should incorporate information developed by recent studies of faulting in the NTS vicinity. Historical seismicity prior to nuclear testing is too sparse to provide a basis for delineation of source zones: hence, the specification of seismic sources has to be developed primarily from the faults.

3. The mapped faults themselves do not have sufficient historic seismicity for their rates to be defined individually on the basis of that seismicity, and, therefore, individual faults cannot be the basis for seismic-rate specification; therefore, the faults have to be aggregated. In this model, the faults were aggregated by differentiating them spatially according to changes in the direction and density of faulting.

4. The boundaries used to differentiate the fault aggregates in 3 were also used to define the seismic source zones. (The faults within these zones maintained a separate identity as source faults.)

5. Seismic rates for the study region were set according to a Gutenberg-Richter fit to the historical rate of magnitude 4.0-5.2 earthquakes prior to 1960 , constrained so that the rate of magnitude 7.0-7.6 events is 3.5 per 10,000 years. This latter value is considered an upper bound for a tectonic regime in which larger magnitude earthquakes are assumed to express themselves in normal faulting (W. Carr and E. Anderson, U.S. Geological Survey, oral commun, 1984).

Given the above considerations, source faults, source zones, and their corresponding seismic rates were defined as follows: 
1. Candidate source faults were obtained from the fault and seismicity map appearing in Rogers and others (1983, plate 1). The fauls appearing on this map are both "mapped" and inferred and have no distinction made as to age. Only faults at least $5-\mathrm{km}$ long are used as source faults. Figure 4 shows the faults used in the model, and figure 5 shows the boundaries separating fault aggregations. These boundaries define source zones for earthquakes smaller than magnitude 5.8 , which were modelled as point-ruptures. The faults define the sources for earthquakes of magnitude larger than 5.8, which were modelled by magnitude-dependent, finite-length ruptures.

2. Because of the large number of zones and the sparsity of the historical data, there were insufficient numbers of earthquakes observed in these source zones for these observed numbers to be used to reliably allocate seismicity to the zones. Accordingly, rates were assigned to zones by means of a procedure analogous to hypothesis testing:

a. Seismicity for magnitudes as low as magnitude 3.4, prior to the time of nuclear testing, was allowed to augment the catalog (see fig. 6 for a geographical plot of the catalog earthquakes used). The observed number of earthquakes per unit area was calculated for each zone (fig. 7); for purpose of illustration, the observed rates were divided into relative-rate categories so that grey-scale shading could be used to indicate rates.)

b. An expected number of earthquakes was calculated for each zone, using the areal rate of seismicity calculated for the entire study area and the area of the zone. (A chi-square test showed that the observed seismicity was significantly different from random at a probability level less than 0.005.) Then each zone was categorized according to whether the observed number of earthquakes was significantly higher or lower than the expected number of earthquakes (according to a Poisson distribution). Two of the 21 zones experienced observed seismicity significantly less than expected, at the 0.05 significance level. Four zones experienced observed seismicity significantly greater than expected, at that same significance level.

c. The two zones having significantly smaller-than-average rates were assigned relative areal rates of $1 / 6$ (compared to an overall average areal rate of 1.0 ). This rate corresponds to the average observed number of earthquakes of these two zones. Three of the four zones having greater-than-average rates were assigned relative rates of 3 , corresponding to the average number of earthquakes observed in the four zones. The fourth zone was assigned a relative rate of 5 , which was the the lowest rate allowing the observed number of earthquakes at the 0.20 significance level. In order to preserve the total 


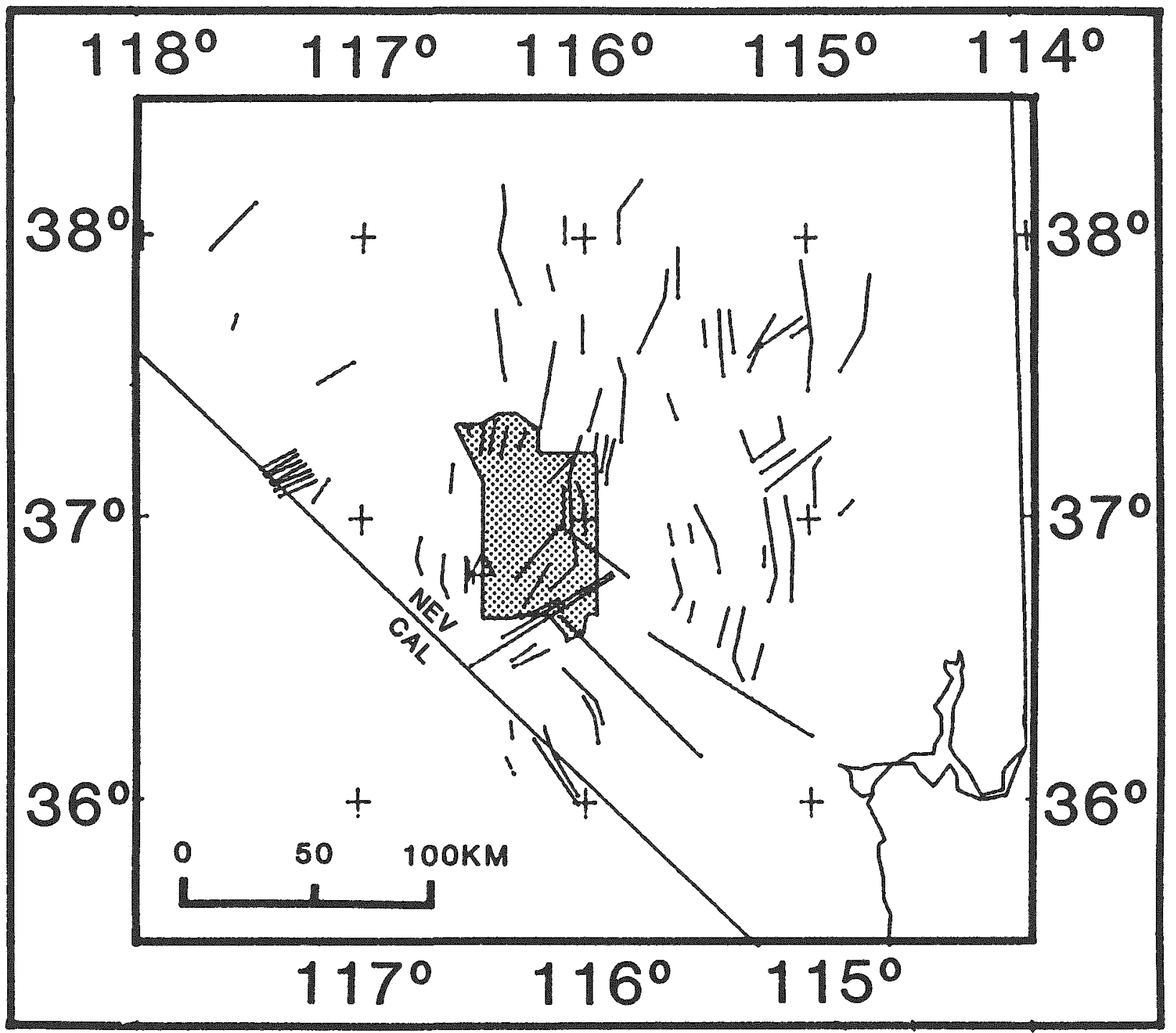

Figure 4. Mapped faults or inferred buried faults, at least $5-\mathrm{km}$ long in $2^{\circ}$ by $2^{\circ}$ area around NTS (from Rogers and others, 1983) (excluding faults in California). The small open triangle indicates the potential waste-disposal facility. The three long faults to the southeast of the site are inferred and may not be continuous. 


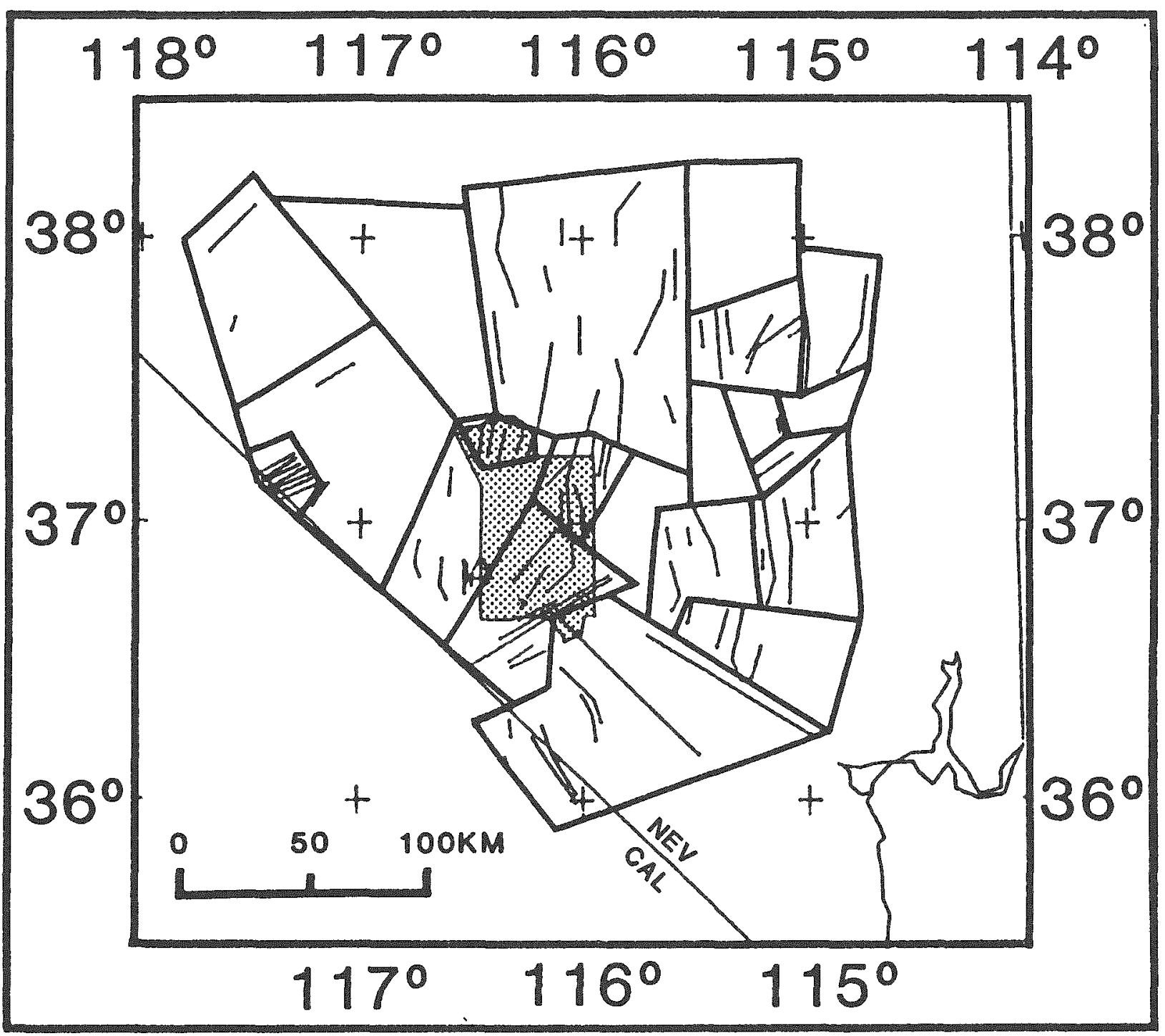

Figure 5. Source zones and source faults for model 2: a particularized subregional model. Source zones are based on direction and density of faults. 


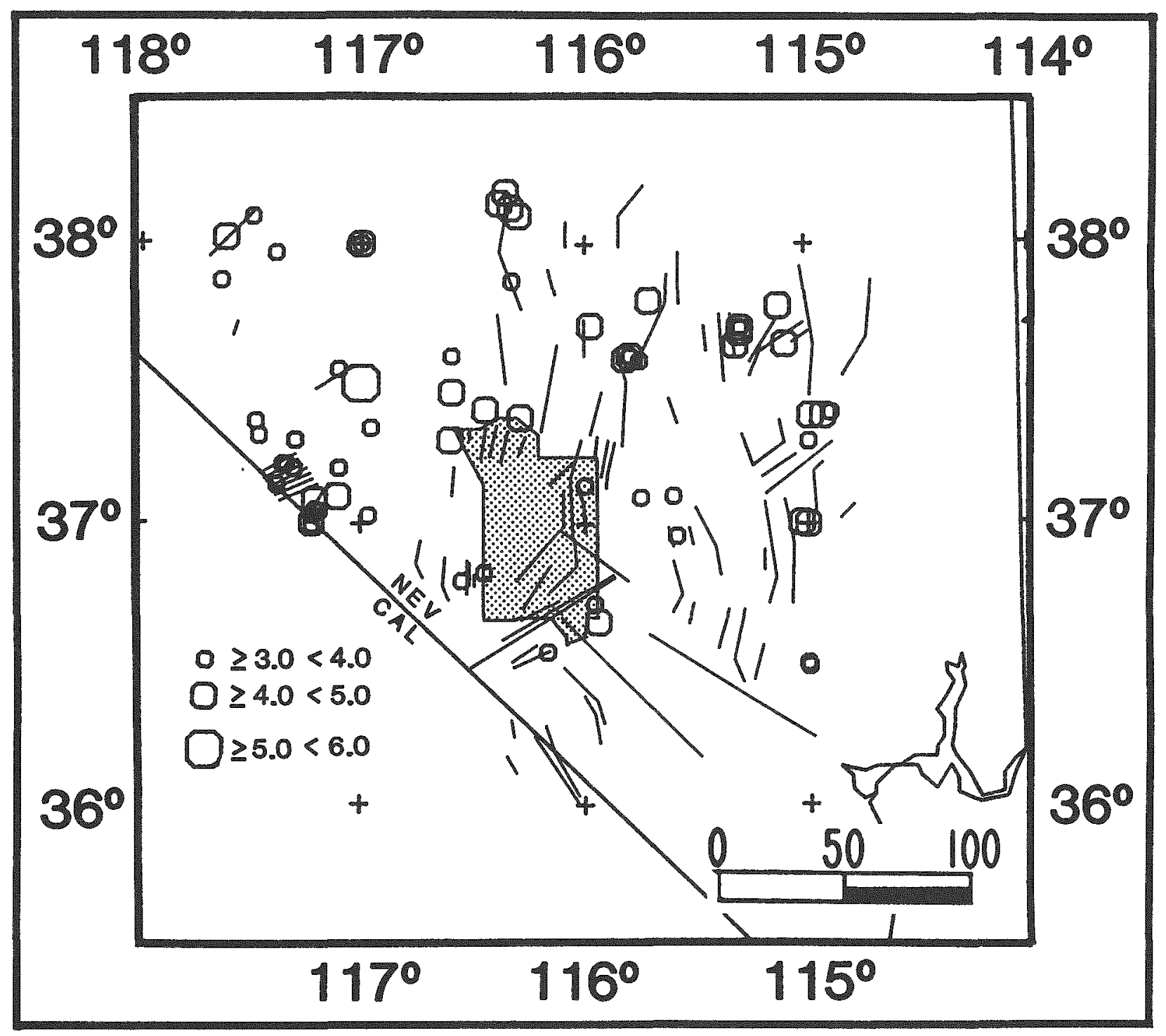

Figure 6. Seismicity of magnitude greater than 3.4, prior to 1960. Small symbols: Magnitude 3.4-4.0; Intermediate symbols: Magnitude 4.0-5.0; Large symbol: Magnitude 5.0-6.0. 


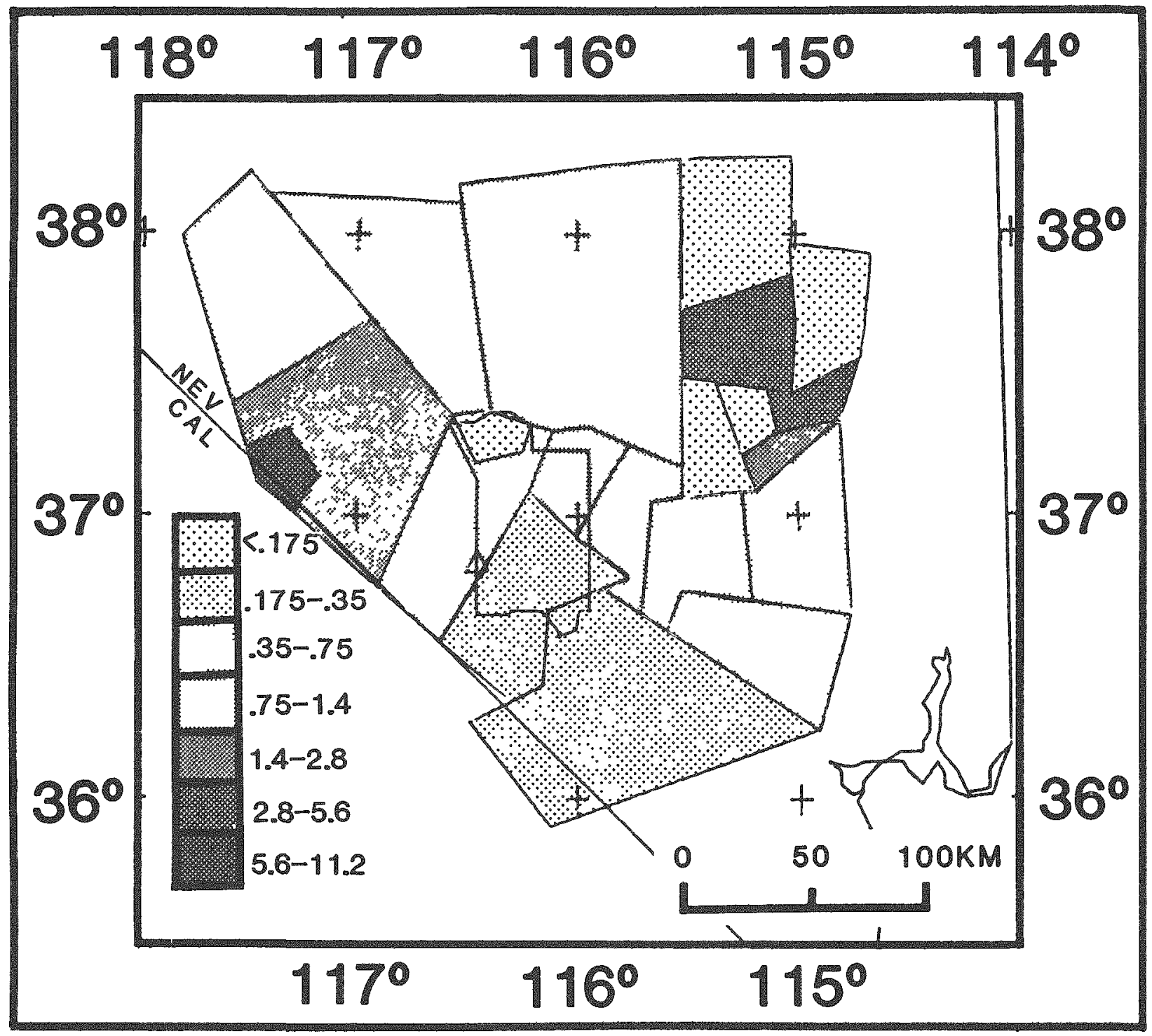

Figure 7. Number of earthquakes per unic area for earthquakes having magnitudes greater than 3.4. Categorized according to relative rate compared to average over whole study area. 
observed seismicity, zones having average areal seismicity rates not significantly different from the overall average rate received a relative rate of $3 / 4$. Figure 8 shows the zones in the four relative-rate categories.

d. The seismicity from the Gutemberg-Richter fit to the study region was allocated to the source zones in accordance with their assigned areal rates times their areas.

3. The above procedure accounts for the modelling of seismicity in the magnitude range 4.0-5.8. We considered several alternatives when deciding how to allocate the seismicity in the magnitude range greater than 5.8 to the model faults.

a. We could have allocated seismicity to the faults in a zone using the same proportion as was used to allocate seismicity to the zone. Zones having many faults tend to have a large total length of faulting. Therefore, the faults in such zones would receive a relatively low rate of seismicity per unit length. Likewise, faults in zones with rew faults would receive a relatively high rate of seismicity per unit length. Therefore, under this allocation the more dangerous faults will tend to be found in the zones with the fewest faults. This seems counter-intuitive.

b. An effect opposite to that found above in (a) would be observed if we allocated seismicity in such a way that all faults have the same seismicity per unit length. Now the rate of occurrence of larger-magnitude earthquakes in a zone depends upon the length and density of faulting in the zone. This is quite an attractive result for the zones having rates near that of the average rate. However, in the low-rate zones, the faults would be disproportionately dangerous, and in the areas of high-rate zones, the faults would be disproportionately inactive.

c. We could have allocated seismicity to faults in proportion to the monitored seismicity appearing within some distance of the fault. This is an attractive proposition except for the major disqualifying problem that, since the monitored seismicity is contaminated with explosion aftershocks, we wouldn't want to use this method until the catalog of monitored seismicity had been properly purged.

Considering these proposals and objections, we chose an allocation method which compromised between points $a$ and $b$, above. The upper-magnitude seismicity was allocated to the zones in the same proportion as was the lower-magnitude seismicity. Then, for the "average-rate" zones as a whole, the upper-magnitude seismicity was pooled and then re-allocated to the faults, according to a common 


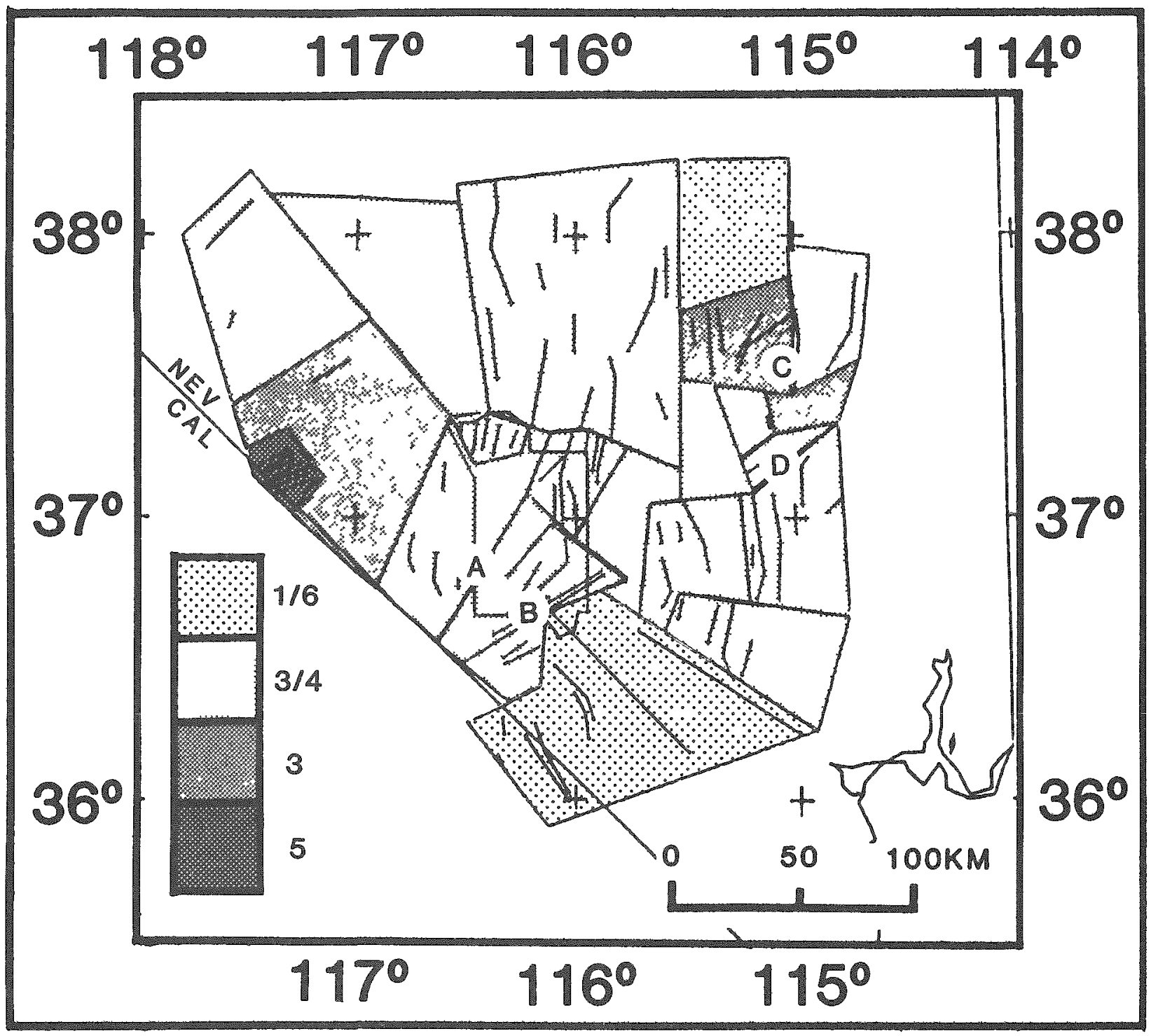

Figure 8. Areal rate reduced to four relative-rate categories and adjusted to preserve total number of earthquakes. Three-quarters was taken as "background rate"; zones with significantly less seismicity than background were assigned seismicity 1/6; and zones with significanty greater areal seismicity were assigned rates 3 and 5. Location $A$ is the potential waste-disposal site, and locations $B, C$ and $D$ are arbitrary locations for which probabilistic ground motions were calculated for purpose of comparison with site $\mathbb{A}$. 
rate per unit length. Thus, in the areas covered by average-rate zones, the hazard due to faulting is dependent upon the length and density of faulting, and. is independent of the local zonal rate. However, in more-active-than-average or less-active-than-average zones, upper-magnitude seismicity allocated to a zone is assigned to the faults appearing in that zone. This allocation gives stronger-than-average seismicity per unit length for faults in the most active zones and weaker-than-average seismicity per unit length for faults in the less-active zones.

4. In this model, the waste-storage site is located at a short distance from two short, and therefore weakly active, faults. (location $\mathbf{A}$ in figure 8). In order to compare the probabilistic ground motions at this site with other sites somewhat differently situated, we chose three other sites: one at a comparable distance from three long faults (B), one about twice as far from three faults in a very active zone (C), and one on a short fault between two longer faults in an average-activity zone (D).

Figure 9 shows a probabilistic ground-motion map of the study area using the source and rates of model 2 , described above. The probabilistic ground-motion hazard at the waste disposal site (location $\mathrm{A}$ ) is modest, intermediate between the median-level hazard and the lower-level hazard on the map. The other three sites are at more hazardous locations.

Figure 10 shows curves of probabilistic ground motion vs. return period for all four sites. For ground motions less than $0.1 \mathrm{~g}$, the curves are somewhat steeper than the reference, point-source curves. This characteristic shows that the ground-motion exceedances at these levels are dominated by earthquakes modelled on faults. For higher ground-motion values, the individual curves show a varying response according to the relative nearness and relative activity of the nearest faults. In general, ground-motion values from model 2 at these sites range from values near reference curve $\mathbf{B}$ to values intermediate between curves $\mathbf{A}$ and $\mathbf{B}$.

Discussion of model 2

The results from model 2 would be expected to be superior to the results obtained under model 1 for two reasons. First, model 2 uses a realistic rather than a generalized source description. The use of a realistic subregional description provides comparative hazard estimates for other sites. Second, whe seismicity 


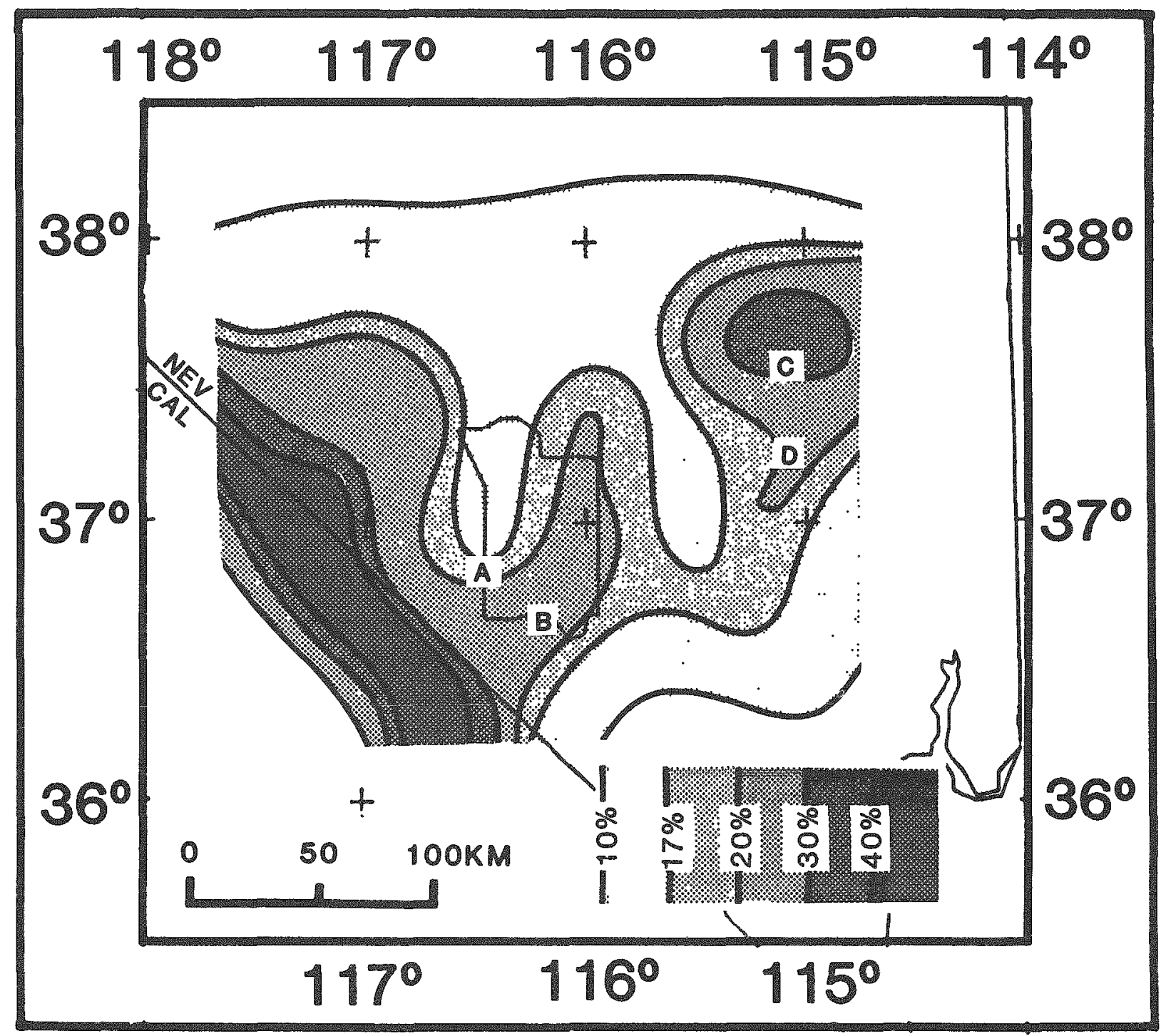

Figure 9. Probabilistic ground-motion hazard map for a return period of 2,500 years. Contours show peak acceleration in percent $g$, having a probability of 0.1 of being exceeded in 250 years. At this level of probability, site $C$ appears to be the most hazardous and site A (the potential waste-storage site) the least hazardous of the four sites. 


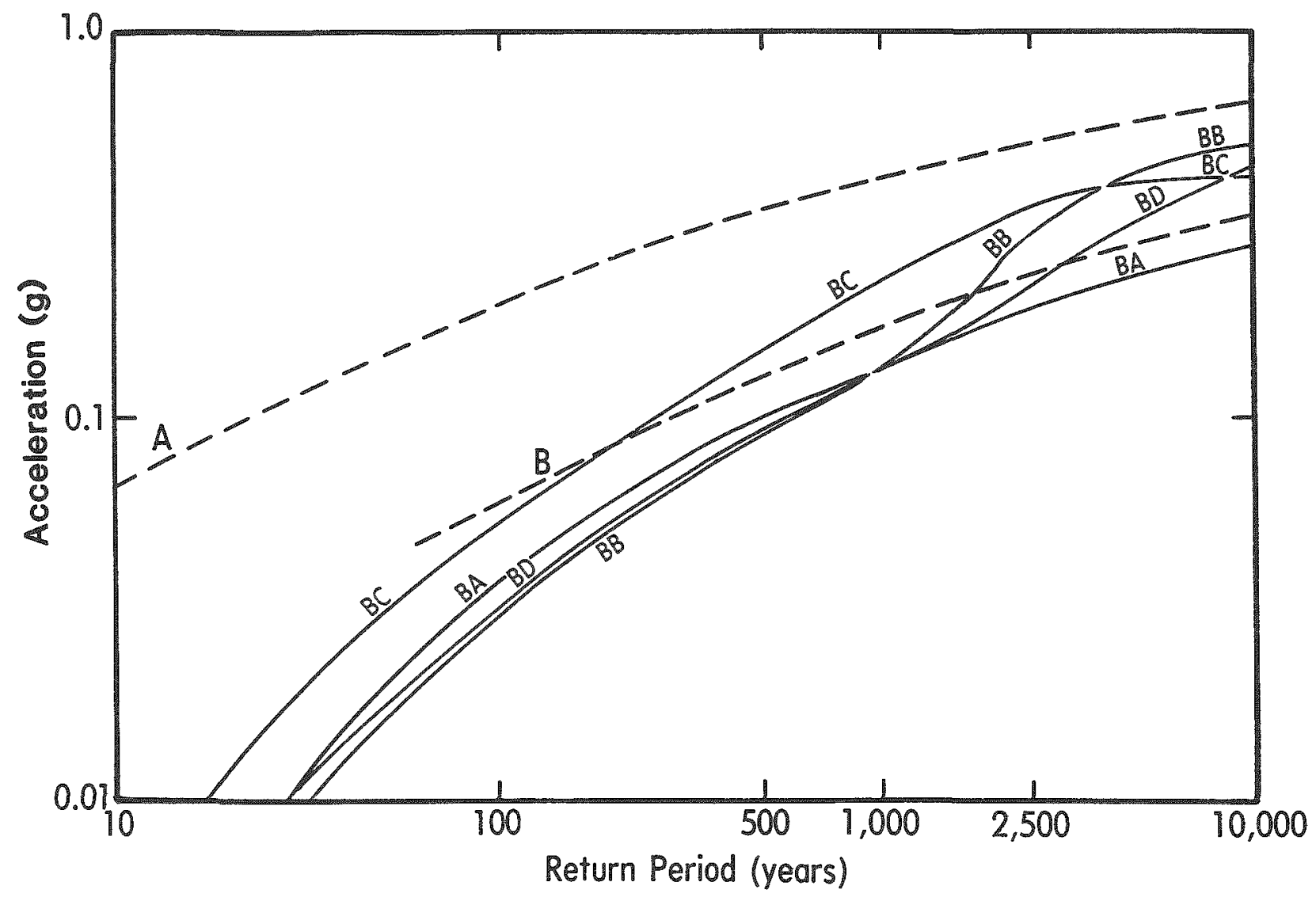

Figure 10. Acceleration vs return-period curves based on model 2 for sites $A, B, C$ and $D$ (site curves are prefized with $\mathbf{B}$, to distinguish them from reference curves). For ground motions less than $0.1 \mathrm{~g}$, the curves are somewhat steeper than the point-source curves $\mathbb{A}$ and $\mathbb{B}$. For higher ground-motion values, the curves show response to the relative nearness and relative seismicity of nearby faults. At sites $B$ and $D$ we see changes related to the increasing effect of the seismicity on nearby faults. Site $\mathrm{C}$ shows a flattening due to the approach to the limiting ground-motion value given by the maximum magnitude at 15-km distance from the site. Site A shows the lowest ground-motion values due to the low rates on the nearby faults. In general, the ground-motion values from model 2 at these sites range from values near reference curve $\mathbb{B}$ to values intermediate between curve $A$ and $B$, depending on the return period. 
estimates have been made from an earthquake catalog which has not been contaminated with nuclear-explosion aftershocks. This second fact alone may be the major reason that the model 2 results are comparable to the curve $B$ values from 1977. However, the model 2 results should not be considered definitive, but rather should be considered interim to some future result. Just as we analyzed model 1 for deficiencies, we should analyze model 2 for deficiencies.

Perhaps the most prominent problem with model 2 is its dependency on a sparse amount of historic seismicity. Because of the sparsity of the historic seismicity, the Gutenberg-Richter curve is not constrained in its rates for mid-magnitude earthquakes, and the b-value obtained in this model (-1.06) depends entirely on the assumed rate for the maximum magnitude earthquakes. A substantial amount of the difference between the model 1 curves and the model 2 curves may derive from the difference between the b-values of the corresponding fits to the seismicity data. $\mathbb{A}$ flatter Gutenberg-Richter curve would be obtained if a geological consensus supported the concept of the possible occurrence of large-magnitude, strike-slip earthquales on the faults. Geologically determined fault recurtence rates for large-magnitude events would be particularly desirable in constraining the high-magnitude end of the Gutenberg-Richter curves.

Another seeming deficiency of model 2 is that the allocation of historical seismicity at the lower-magnitude levels permitted only four rate categories. More categories might have been possible if zones had been categorized by geologic characteristics. For example, the zones could have been categorized by common fault orientation, supposing that orientation in the current stress regime might affect the seismic rate in the vicinity of the faults. Alternatively, it might have been possible to categorize the zones by common fault density, supposing that fault density and seismic activity are related. Either categorization would have produced additional sets of possible rates by which to test the significance of the observed rates and might have resulted in more categories of assigned areal seismic rates. It is not possible to know whether a significantly different allocation of seismicity would have resulted, but some insight into the tectonic regime would have been gained by data on the relative rates observed for the grouped zones. Future work should. test these possibilities.

It is important not to overlook a significant difference between model 1 and model 2 in the modelling of large-magnitude earthquake sources. In model 2 , the larger-magnitude earthqukes occur only on faults, which are generally not located at zero distance from the sites. In model 1, large-magnitude earthquales were also 


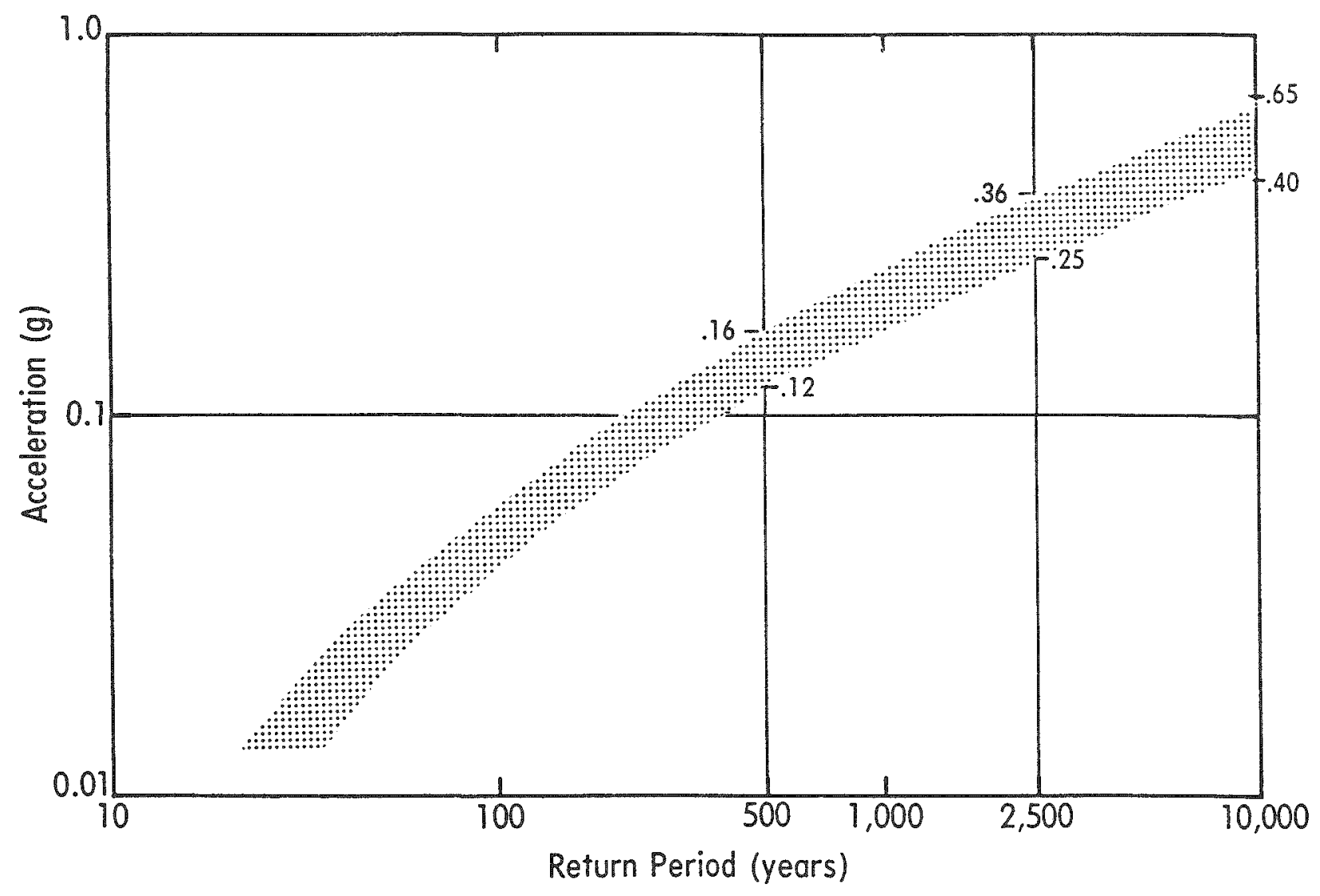

Figure 11. Region for curves of acceleration vs return period for sites whose seismic characteristics are intermediate between those of site $\mathbf{A}$ and site $\mathrm{C}$. Curves for these two sites represent a reasonable range of estimates for the site of the proposed facility, accounting for possibility of discovery of relatively active, somewhat longer faults in the vicinity of the proposed facility, but not adjacent to the site. Calculations now include effect of variability in acceleration attenuation function, thus producing higher (and smoother) estimates than shown in figure 10. 
possible as point sources at zero distance. It would take some hard thinking to decide which of these two treatmeats should be preferred when the complete tectonic picture is not well known.

From the above discussion, it is reasonable to assert that a truer representation of the relative hazard at the potential waste-disposal site would be a curve intermediate between the model-1 and model-2 curves, probably closer to the model-2 curves. Among the model-2 curves, those for site $\mathbf{A}$ and site $C$ represent a reasonable range of estimates for the site of the proposed facility, accounting for the possibility of discovery of relatively active, somewhat longer faults in the vicinity of the proposed facility, but not adjacent to it. Up to now we have presented curves calculated without regard to attenuation variability, in order to permit comparisons with other studies. In figure 11, we present the range of values between curves for site $A$ and site $C$, taking into account attenuation variability, calculated using a standard deviation of 0.5. This range should serve as an interim estimate of probabilistic accelerations for the site of the proposed facility.

\section{Conclusions}

Models using generalized local sources and varying upper-bound magnitudes produce probabilistic ground-motion values comparable to the upper-bound estimates of Rogers and others (1977). These ground motion values are believed to be excessively high for two reasons:

1. The estimated recurrences for the large-magnitude earthquakes are too high compared to the geologists' estimates for recurrence of these magnitudes in a normal-faulting regime.

2. There appears to be significant contamination from nuclear-explosion aftershocks as far as $50 \mathrm{~km}$ from the site of the explosions.

A model using the direction and density of mapped faults to define subregional sources, and using seismicity prior to 1960 to set seismic rates, produces probabilistic ground motions comparable to the lower-bound estimates of Rogers and others (1977). These ground motions may be too low for the following reasons:

1. There is too little pre-1960 seismicity to allow for much differentiation in source-zone seismicity. Most zones must, for statistical reasons, be assumed to 
have an overall average rate of seismicity, which is relatively low.

2. Seismic rates for the larger-magnitude earthquakes have been constrained using geological estimates of recurrence in a normal-faulting regime. The rates might be considerably higher (by as much as a factor of 10) if extrapolation of current seismicity is a guide. However, these larger earthquakes would have to occur in a strike-slip regime or some other regime which permits large earthquakes to take place without substantial vertical faulting.

For the above reasons, the probabilistic ground-motion hazard at the potential waste facility is likely to be overestimated by the first model and underestimated by the second model. The following activities are proposed so that more reliable probabilistic ground-motion estimates may be carried out:

1. Purge the catalog of nuclear-test aftershocks in order that the vast amount of monitored seismicity can be used to refine source-zone rates.

2. Produce a more refined subregional model. In particular, test a model in which tectonic models guide the use of fault direction in setting source seismicity rates.

3. Derive recurrence estimates for large-magnitude earthquakes using regional strain-rate models.

4. Alternatively, derive recurrence estimates for strine-slip events using recent geological studies on strike-slip recurrence for faults in the immediate vicinity of the proposed facility.

5. Revise magnitude estimates for historical earthquakes. Rogers and Harmsen (U.S. Geological Survey, oral commun., 1985) have recently proposed that NTS-vicinity earthquakes may have had their magnitudes seriously overestimated by California networks, due to the relatively low rate of attenuation of seismic waves from southern Nevada along paths to California. If so, the seismicity rates for larger-magnitude earthquakes may be more in line with the low recurrence rates estimated by geologists.

6. Produce attenuation functions for strong grownd motion at NTS. Absolute rather than relative ground-motion estimates may be achieved using attenuation models for the NTS vicinity calibrated from the data from recent monitoring.

7. Test the effect of very low angle detachment faulting assumed to underlie much of the test-site vicinity. Though it is unlikely that data can be found for estimating the recurrence of such events, probabilistic ground-motion calculations can suggest how high the recurrence rates might be without appreciably affecting the results obtained from other models. 


\section{Acknowledgments}

We wish to thank Will Carr, Ernie Anderson, Al Rogers, and Steve Harmsen for their helpful advice. Enie Anderson and Ken Campbell provided critical reviews. The work was performed in cooperation with the U.S. Department of Energy, Nevada Nuclear Waste Storage Investigations Project. 


\section{References}

Algermissen, S.T., and Perkins, D.M., 1976, A probabilistic estimate of maximum acceleration in rock in the contiguous United States: U.S. Geological Survey Open-File Report 76-416, 45 p.

Algermissen, S.T., Perkins, D.M., Thenhaus, P.C., Hanson, S.L., and Bender, B.L., 1982. Probabilistic estimates of maximum acceleration and velocity in rock in the contiguous United States: U.S. Geological Survey Open-File Report 82-1033, 99 p.

Rogers, A.M., Harmsen, S.C., Carr, W.J., and Spence, W., 1983, Southern Great Basin Seismological Data Report for 1981 and Preliminary Data Analysis: U.S. Geological Survey Open-File Report 83-669, 240 p.

Rogers, A.M., Perkins, D.M., and McKeown, F.A., 1977, A preliminary assessment of the seismic hazard of the Nevada Test Site region: Bulletin of the Seismological Society of America, V. 67, p. 1587-1607. 